\title{
RADIATION-INDUCED ANGIOSARCOMA OF THE BREAST - FOUR CASE REPORTS
}

\author{
KATARINA ANTUNAC \\ Division of Radiotherapy and Medical Oncology, University Hospital for Tumors, \\ Sestre milosrdnice University Hospital Center, Zagreb, Croatia
}

\begin{abstract}
Summary
Secondary breast angiosarcoma is a known but rare late side-effect of breast cancer radiotherapy. Here are four patients reported, irradiated in University Hospital for Tumours due to breast cancer who developed secondary angiosarcoma several years after irradiation. Two patients eventually died of angiosarcoma. Tumour has various appearances and might not be visible on mammography or ultrasound, regularly used in order to detect locoregional relapse of breast cancer timely. Surgery remains the primary therapeutic approach.
\end{abstract}

KEYWORDS: breast cancer, angiosarcoma, secondary tumors

\section{Sažetak}

\section{ANGIOSARKOM DOJKE UZROKOVAN ZRAČENJEM- PRIKAZ 4 SLUČAJA}

Sekundarni angiosarkom dojke poznata je rijetka kasna komplikacija zračenja dojke. Prikazane su 4 bolesnice u kojih se razvio sekundarni angiosarkom nekoliko godina po završetku zračenja. Dvije bolesnice umrle su od posljedica angiosarkoma. Tumor je različitog izgleda i ne mora nužno biti vidljiv na mamografiji ili ultrazvuku, pretragama koje se uglavnom koriste za rano otkrivanje lokoregionalnog recidiva raka dojke. Kirurški zahvat i dalje ostaje prvi terapijski izbor.

KLJUČNE RIJEČI: rak dojke, angiosarkom, sekundarni tumori

\section{INTRODUCTION}

Breast angiosarcoma is a rare, aggressive malignancy of vascular endothelium. Radiotherapyinduced angiosarcoma is cutaneous in origin, arising from the dermis and subcutis of the irradiated skin and may involve the underlying breast tissue. It is usually multifocal and widely distributed within the RT (radiation therapy) field (1) and presents mostly as reddish-purple patches with surrounding hematoma, plaques, erythematous nodules, lumps, skin dimpling or thickening. Rarely, it is associated with distant metastases. Being predominantly skin/subcutaneous malignancy, it might not be visible on mammography or ultrasound. Mammography can show skin thickening or increased density but cannot reliably distinguish between healthy tissue and angiosarcoma. Ultrasonically it is usually seen as a hyperechogenic mass, but in one series of 21 patients, it was reported to be misdiagnosed in about one third (2).

The absolute risk of secondary angiosarcoma is estimated to be less than $0.5 \%$ and the median latency period is about 4-8 years (3). However, its incidence is expected to rise since breast-conserving surgery followed by radiotherapy has become 
standard of care in patients with early-stage breast cancer and survival rates in this group of patients are rising. The most common salvage treatment performed is a simple mastectomy. Data on chemotherapy and radiotherapy, both in (neo)adjuvant and palliative setting are limited.

Here are presented 4 cases of breast angiosarcoma diagnosed in patients that were previously irradiated after breast-conserving surgery.

\section{RESULTS}

\section{Case 1}

At the age of 73 patient underwent right breast-conserving surgery and axillary node clearance for an ER and PR positive and Her2 negative $15 \mathrm{~mm}$ grade I invasive lobular carcinoma. No evidence of a tumor was found in axillary lymph nodes $(0 / 15)$. Surgery was followed by radiotherapy and adjuvant hormonal therapy (letrozole) for five years. The right breast was irradiated with 50 Gy in 25 fractions 3D CRT (three- dimensional conformal radiotherapy). A year earlier she has had a left nephrectomy due to renal carcinoma, which was staged as pT3N0. The patient had regular follow up visits with mammography and breast ultrasound alternatively every six months.

Seven years after radiotherapy completion patient presented with an itching papule sized about $1 \mathrm{~cm}$, surrounded with a hematoma and skin thickening on an area of about $2 x 5 \mathrm{~cm}$ just below the right breast nipple. Cytology revealed malignant mesenchymal tumor. Chest $X$-ray and abdominal ultrasound showed no evidence of the disease and the patient was referred for radical mastectomy. Histology revealed high-grade angiosarcoma sized $7 \mathrm{~cm}$ and located subepidermal and in subcutaneous fat tissue. Immunohistochemistry confirmed tumor cells expressing CD 31 and factor VII with weak expression of CD 34 and C-myc. Surrounding tissue was CK7 positive. The closest margin measured $10 \mathrm{~mm}$.

Three months after surgery a large recurrence appeared, covering the whole right half of the thoracic wall and spreading to her left breast. The whole- body CT scan showed no evidence of metastases. A left radical mastectomy with excision of a tumor and a flap reconstruction was performed. Histology revealed a 17x $12 \mathrm{~cm}$ angiosarcoma. Tumour infiltrated fat tissue, underlying muscle, and dermis. Left breast was free from a tumor.

Two months after surgery patients had large recurrence on her right chest wall $(20 \times 15 \mathrm{~cm})$ with erythema, induration, and multiple lumps up to 3 $\mathrm{cm}$. She complained of itching and occasional pain. No systemic antineoplastic treatment was administered. One month later, nine months after the first sign of angiosarcoma, the patient died.

\section{Case 2}

At the age of 79 , the patient was diagnosed with right breast cancer and underwent breastconserving surgery with axillary dissection. A 12 $\mathrm{mm}$, grade 2 ductal invasive carcinoma, ER + and $\mathrm{PR}+$, Her2 neg was found. Axillary lymph nodes were negative, $0 / 10$. Hormonal therapy with anastrozole for five years was prescribed and her right breast was irradiated with 50Gy in 25 fractions of conventional radiotherapy. Regular follow up visits took place every 6 months. The patient had mammographies, breast ultrasound, and 1 MRI, all findings showed no evidence of the disease.

Seven years after completion of radiotherapy patients came with 3 livid plaques up to $2 \mathrm{~cm}$ and skin thickening of her right breast. A biopsy was performed which showed no evidence of angiosarcoma. MRI revealed skin thickenings, measuring 2 and $1 \mathrm{~cm}$. The patient underwent wide excision. Tumour within reticular dermis with infiltration of subcutis was histologically found, composed of atypical mitotically active endothelial cells forming vascular channels. Immunohistochemistry confirmed tumor cells expressing CD 31. Tumour was completely removed.

Eleven months later MRI showed skin thickening and several enhancing lesions within the breast parenchyma. An abdominal ultrasound suggested no evidence of metastatic spread. After FNA confirmation of angiosarcoma, the patient had a radical mastectomy. Histology showed nodules up to $11 \mathrm{~cm}$ with CD 31 expression.

Two months later a recurrent lesion was again excised and pathology confirmed angiosarcoma. After two months one more excision had to be done. According to histological result, the patient had several tumors up to $11 \mathrm{~cm}$ within dermis and subcutis which infiltrated the underlying muscle. Immunohistochemically tumors stained positive for CD 31 and factor VII and negative on CK7 and CD 34. 
In just three months patient suffered an extensive unresectable recurrence and succumbed two years after the initial angiosarcoma diagnosis.

\section{Case 3}

A 64- year old patient has had right breastconserving surgery with axillary node clearance due to a triple negative ductal invasive carcinoma grade III sized $7 \mathrm{~mm}$, Ki67 20\%. Axillary lymph nodes contained no tumor (0/17). She received six cycles of AC chemotherapy and underwent right breast adjuvant irradiation with 50 Gy in 25 fractions, followed by boost doses, 3x 3 Gy 3D CRT. She had regular follow up visits with laboratory check-ups and yearly alternating breast ultrasound/mammography examinations, showing no evidence of the disease.

Six years after radiotherapy she noticed a red area on her right breast. Ultrasound showed just skin thickening. A biopsy followed by wide excision was performed. Histology revealed grade III angiosarcoma, sized $3 \mathrm{~cm}+$ foci located in the dermis and subcutaneous fat tissue with free surgical margins. Immunohistochemistry confirmed that the tumor cells expressed CD 31, collagen IV and laminin. Chest X-ray and abdominal ultrasound did not show any evidence of metastatic spread. free.

Six months after surgery patient is still tumor

\section{Case 4}

This patient was diagnosed with right breast cancer at the age of 55. Breast-conserving surgery and axillary dissection were performed and histology revealed ductal invasive carcinoma grade I, sized $10 \mathrm{~mm}$, ER and PR positive, Her2 negative, axilla 0/14. Conventional postoperative irradiation of right breast was performed, the patient received 50 Gy in 25 fractions, followed by a boost 4x 2,5 Gy and started with hormonal therapy: tamoxifen switched to anastrozole two years later.

Three years after primary treatment patient complained of bone pain; X-ray showing osteolytic lesion in her right tibia sized $55 \mathrm{~mm}$, later irradiated with 1x 8Gy. Anastrozole has been replaced with exemestane and clodronate administration was initiated. The patient continued to have regular follow up visits with mammographies, breast ultrasounds, and bone scans, all of them being inconspicuous.
Eight years post-irradiation patient presented with erythematous skin thickening on her right breast, sized about $5 \mathrm{~cm}$. Biopsy revealed angiosarcoma with positive margins. Immunohistochemically a tumor stained positive for CD 34, CD 31 and factor VIII. A simple mastectomy followed, histology did not show any a residual tumor. CT scan of chest, abdomen, and pelvis showed no evidence of distal spread. Hormonal treatment was discontinued.

Four years later the patient is still without evidence of the disease, both primary breast, and angiosarcoma (except for the described osteolytic metastasis in right tibia) and she is not receiving any cancer-specific therapy.

\section{DISCUSSION}

Secondary angiosarcomas are a well known but infrequent complication of breast cancer radiation treatment. All four patients had breast-conserving surgery followed by radiotherapy, $50 \mathrm{~Gy}$ in 25 fractions. Two younger patients additionally received a boost dose on tumor bed, one 3x 3 Gy and the other one $4 \times 2,5 \mathrm{~Gy}$. Two patients were irradiated with 3-D conformal technique and two with a 2-D conventional technique. All patients had right breast cancer with negative lymph nodes; therefore, in all patients only right breast was irradiated. The period between radiotherapy and occurrence of angiosarcoma was six, seven, seven and eight years. Adjuvant breast cancer radiotherapy after breast-conserving surgery is an effective treatment resulting in significant reduction of both local and systemic recurrence and better cancer-specific and overall survival (4). However, according to contemporary data, adjuvant radiotherapy is no longer justified in patients with pT1-2N0 HR+ tumors aged more than 70 years at the time of diagnosis and receiving hormonal therapy. Although rates of locoregional recurrence are lower with radiotherapy, it does not contribute to overall or cancer-specific survival in that subgroup of patients (5). Therefore, two of these patients developing angiosarcoma, today would not meet criteria for adjuvant radiotherapy and would not be irradiated. Unfortunately, exactly they had an aggressive form of the disease and eventually died of it. Also, these two patients, although without significant comorbidity, were of 
advanced age at the time angiosarcoma was diagnosed, namely 80 and 86 , which might have affected their course of the disease.

Three patients had hormone positive disease and were receiving only hormonal therapy as a systemic treatment, and one patient was given chemotherapy because of a triple negative disease. One patient had an oligometastatic breast cancer and was irradiated due to bone metastasis before angiosarcoma occurred. Nevertheless, the patient is still well and without any tumor symptoms. None of these four patients with angiosarcoma developed distant metastases.

After being treated for breast cancer, all patients had regular mammographies and breast ultrasound examinations in order to discover possible locoregional relapse at its earliest stage. Since angiosarcoma is predominantly skin/subcutaneous lesion, it is not necessarily detectable with these methods, which was the case in all our patients (6). That stresses the importance of inspection and palpation of the breast/irradiated area at each follow-up visit.

After being diagnosed with angiosarcoma, two patients had a radical mastectomy, one had radical mastectomy upon angiosarcoma, and one had wide excision. According to some authors, possible excision of all irradiated skin and thoracic wall soft tissue might be connected with the improved survival of these patients (3). Experience with this subgroup of patients is different: 2 patients after mastectomy died of angiosarcoma, but one patient is alive and with no evidence of the disease after mastectomy. The patient only having wide excision is without signs of the disease 6 months later, albeit this follow up period is probably too short to draw any conclusion regarding such approach efficacy.

\section{CONCLUSION}

Secondary breast angiosarcoma can occur several years after completion of breast cancer ad- juvant radiotherapy. Being predominantly skin and subcutaneous tissue located lesion, it is easily visible during regular follow up visits but its nonspecific appearance can sometimes delay the diagnosis. Both patients and clinicians should be vigilant of any skin changes for its early detection. Surgical treatment still remains a standard approach, though with various outcomes.

\section{REFERENCES:}

1. Li G Z, Fairweather M, Wang J, Orgill DP, Bertagnolli MM, Raul CP. Cutaneous radiation-associated breast angiosarcoma. Radicality of surgery impacts survival. Ann Surg. 2017;265:814-20.

2. Abbot R, Palmieri C. Angiosarcoma of the breast following surgery and radiotherapy for breast cancer. Nature. 2008;12(5):727-36.

3. Styring E, Klasson S, Rydholm A, Vult von Steyern F. Radiation-associated angiosarcoma after breast cancer: improved survival after excision of all irradiated skin and soft tissue of the thoracic wall? A report of six patients. Acta Oncol. 2015;54(7):1078-80.

4. Early Breast Cancer Trialists' Collaborative Group (EBCTCG), Darby S, McGale P, Correa C, Taylor C, Arrigada $\mathrm{R}$ et al. Effect of radiotherapy after breast-conserving surgery on 10-year recurrence and 15-year breast cancer death: meta-analysis of individual patient data for 10,801 women in 17 randomised trials. Lancet. 2011;378:1707-16.

5. Chesney TR, Jin JX, Rajaee N, Tricco AC, Fyles AW, Acuna SA, et al. Tamoxifen with radiotherapy compared with tamoxifen alone in elderly women with early-stage breast cancer treated with breast conserving surgery: a systematic review and meta-analysis. Radiother Oncol. 2017;123:1-9.

6. Arora TK, Terracina KP, Soong J, Idowu MO, Takabe K. Primary and secondary angiosarcoma of the breast. Gland Surg 2014;3(1):28-34.

Corresponding author: Katarina Antunac, Division of Radiotherapy and Medical Oncology, University Hospital for Tumors, Sestre milosrdnice University Hospital Center, Ilica 197, 10000 Zagreb, Croatia. e-mail: katarina. antunac@zg.htnet.hr 